Plant Tissue Cult. \& Biotech. 25(1): 37-46, 2016 (June)

$\overline{\text { PTC\&B }}$

\title{
Influence of Medium Component on In vitro Propagation of Thai's Endangered Orchid: Bulbophyllum nipondhii Seidenf.
}

\section{Wittaya Pakum, Santi Watthana ${ }^{1,2}$, Kanok-orn Srimuang ${ }^{3}$ and Anupan Kongbangkerd*}

Plant Tissue Culture Research Unit, Department of Biology, Faculty of Science, Naresuan University, Phitsanulok-65000, Thailand

Key words: Bulbophyllum nipondhii, Organic supplement, Seed germination, Propagation

\begin{abstract}
In vitro propagation of a rare orchid, Bulbophyllum nipondhii was carried out. Five different media were tested to find the suitable medium for seed germination and seedling development. The tangible results were obtained on VW medium. To assess the effect of pollination types on seed germination and seedlings development, seeds derived from different self-, cross- and open-pollination were examined. Open-pollinated seeds produced the best germination and the highest seedling development, followed by cross- and self- pollination. VW medium was supplemented with $0,25,50$ or $75 \mathrm{~g} / 1$ potato extract (PE) and 0, 50, 100, 150 or $200 \mathrm{ml} / \mathrm{l}$ coconut water $(\mathrm{CW})$ to identify their most suitable concentration. PE $(75 \mathrm{~g} / \mathrm{l})$ with $100 \mathrm{ml} / \mathrm{l} \mathrm{CW}$ was found to be best combination.
\end{abstract}

\section{Introduction}

An epiphytic orchid, Bulbophyllum nipondhii Seidenf., is classified in section Chirropetalum Lindl. The mature plant has small pseudobulbs (approximately 1 $\mathrm{cm}$ high of which each pseudobulb has one leaf, and inflorescences bearing 1 - 10 purple flowers. So for, this species has only been found in Thailand (Seidenfaden 1985, Pedersen 2005) and China (Ye and Li 2012). In Thailand, B. nipondhii is restricted for growing merely on hill evergreen forests in Phuluang Wildlife

*Author for correspondence: <anupank@nu.ac.th>. ${ }^{1}$ Queen Sirikit Botanic Garden, P.O. Box 7, Mae Rim, Chiang Mai 50180, Thailand. ${ }^{2}$ School of Biology, Institute of Science, Suranaree University of Technology, 111 University Avenue, Suranaree Subdistrict, Muang District, Nakhon Ratchasima 30000, Thailand. ${ }^{3}$ Department of Biotechnology, School of Agriculture and Natural Resources, University of Phayao, Phayao 56000, Thailand. 
Sanctuary (PLWS), Loei Province. Nowadays, global warming seems to be the main influence on orchid survival, especially of the epiphytic orchid (Seaton et al. 2010). Many orchids are considered to be endangered species which may become extinct. Hence, appropriate conservation management is needed to recover their natural population levels (Cribb et al. 2003).

Many orchid species have been successfully propagated in vitro since Knudson (1922) showed that orchid seed can be germinated in artificial media. In vitro germination of orchid seed allows the production of a large number of seedlings. However, the seed germination rate of each orchid species is particularly depending on the composition of culture media (Arditti and Ernst 1993). The content of macro- and micronutrients in media is one of the important factors affecting the success of in vitro orchid propagation (Churchill et al. 1972). Additionally, the supplementation of culture media with undefined organic substances like potato extract (PE) and coconut water (CW) can increase the proliferation rate and growth of orchid seedling (Rahman et al. 2004, Kaur and Bhutani 2012, Chen et al. 2014). However, their effects are based on the concentrations of organic supplements, explants type, and orchid species (Thorpe et al. 2008, Molnár et al. 2011). In addition, the germination achievement of orchid seed often depends on pollination aspects. Seeds derived from self- and cross pollination particularly affect seed viability and enhance seed germination (Bellusci et al. 2009).

Although Bulbophyllum has a large number of species, only a few reports on in vitro culture have been published (Bhadra et al. 2004, Than et al. 2009). Furthermore, in vitro propagation of $B$. nipondhii has also never been published. Therefore, the objective of the present study was to establish an efficient micropropagation method of $B$. nipondhii for future re-introduction into their natural habitat.

\section{Materials and Methods}

Three progeny lines of Bulbophyllum nipondhii Seidenf. were produced through self-, cross-, and open-pollination at PLWS, Thailand. During the anthesis mature inflorescences were self-pollinated by using hand pollination and covered by fine nylon mesh. Meanwhile they also were emasculated and cross-pollinated from different plants. For the open-pollination, the progeny was allowed to randomly pollinate by natural pollinators. After 12 months of pollination, mature capsules were harvested and kept at $10^{\circ} \mathrm{C}$ before further use.

The capsules were washed in tap water, submerged in sterilized solution (5\% $\mathrm{v} / \mathrm{v}$ bleach solution and 1\% v/v detergent) for 15 minutes and dipped in $70 \%$ $(\mathrm{v} / \mathrm{v})$ alcohol and finally flamed twice with a spirit burner in a laminar flow 
cabinet. The seeds were aseptically taken out by scalpel and a pair of forceps and mixed together for use in the further experiments.

Two basal culture media, VW (Vacin and Went 1949) and MS were used to determine asymbiotic seed germination and seedling development on in vitro. The VW and half strength of VW media were modified by $50 \mathrm{~g} / \mathrm{l}$ potato extract (PE) and $150 \mathrm{ml} / \mathrm{l}$ coconut water (CW). The $\mathrm{pH}$ was adjusted to 5.2. The PE was prepared from small pieces of peeled potatoes and then boiled in distilled water $(200 \mathrm{ml})$ for 5 minutes. The supernatant was filtered through cheesecloth. The $\mathrm{CW}$ was filtered through cheesecloth before use. The $\mathrm{pH}$ of MS, $1 / 2 \mathrm{MS}$ and $1 / 4 \mathrm{MS}$ were adjusted to 5.7. All media were poured in test-tubes, and autoclaved at $121^{\circ} \mathrm{C}, 1.05 \mathrm{~kg} / \mathrm{cm}^{2}$ pressures for 15 minutes. They were slanted at room temperature. Six developmental stages of asymbiotic germination of B. nipondhii seeds were recorded under a stereoscopic microscope following Yamasaki and Miyoshi (2006). Stages 1, 2, 3 and 4 were represented by no development of seed, by swollen embryo, embryo enlargement and testa rupture (germination stage), by protocorm formation with acute apex and rhizoid appearance, first leaf appearance, and by second leaf, root appearances, respectively (Fig. 1a, b). Data were analyzed using ANOVA, and means were compared by using DMRT.

To evaluate the most effective medium for promoting seed germination and seedling development, the cross-pollinated seeds were sown on five culture media with approximately 300 - 400 seeds per test tube and conducted with six replicates. These cultures were incubated at $25 \pm 2^{\circ} \mathrm{C}, 40 \mu \mathrm{mol} / \mathrm{m}^{2} / \mathrm{s}$ light intensity, and 12 hrs light photoperiod for 4 months. The seed germination and seedling development were recorded monthly after culturing. Data were analyzed as mentioned above.

For explant proliferation, the leaves and roots of plantlets with pseudobulbs 5 - $10 \mathrm{~mm}$ height, produced from cross pollination, were cut off. Only the pseudobulb was grown on VW (with $20 \mathrm{~g} / 1$ sucrose, $7 \mathrm{~g} / \mathrm{l}$ agar and $2 \mathrm{~g} / \mathrm{l}$ activated charcoal) supplemented with the combination of PE and CW. Twelve treatment combinations of individual PE (25, 50 and $75 \mathrm{~g} / \mathrm{l})$ were combined with CW (50, 100, 150 and $200 \mathrm{ml} / \mathrm{l})$, respectively and without PE and CW was used as a control. All treatments were incubated at $25 \pm 2{ }^{\circ} \mathrm{C}, 40 \mu \mathrm{mol} \mathrm{m} / \mathrm{s}$ light intensity, and $12 \mathrm{hrs}$ light photoperiod for 6 months. At the end of treatment, the seed germination and seedling development were recorded and analyzed.

\section{Results and Discussion}

Five modified media (VW, $1 / 2 \mathrm{VW}, \mathrm{MS}, 1 / 2 \mathrm{MS}$ and $1 / 4 \mathrm{MS}$ ) were used to determine the most effective one for seed germination, and seedlings development of the cross-pollinated line of Bulbophyllum nipondhii. The results revealed that majority 
seeds did not germinate (defined as the stage 1) in one month after culture. After two months most of the seeds (more than $80 \%$ ) in all modified media germinated and developed, defined as the stages 2 and 3 (data not shown). Of five media, the number of seedlings developed (at stage 4 ) and cultured on VW (29\%) and $1 / 2 \mathrm{VW}$ (24\%) were higher than rest of the three MS media (range 1 - 2\%) (data not shown).

At four months, the percentage of seed germination (from stages 2 - 5) cultured on the modified VW and MS basal media showed insignificant difference (Table 1). However, the percentage of seedling development (from stages 4 - 5) cultured on two VW basal media had higher than three MS basal media (Table 1). Of five media, the VW gave the highest seedling development at stage 5 (34\%). Moreover, the results found that the $1 / 2 \mathrm{VW}, 1 / 4 \mathrm{MS}, 1 / 2 \mathrm{MS}$ and MS showed (at stage 5) 24.0, 1.9, 1.8, and $0.9 \%$ of seedling development, respectively (Table 1). These results indicated that the VW medium was the most effective for seed germination and seedling development.

It had been reported that the different concentrations of nitrogen $(\mathrm{N})$ and phosphorus $(\mathrm{P})$ play an important role for growth and development of various orchid species (Dijk and Eck 1995). Our results showed that the VW, containing higher P level $(3.77 \mathrm{mM})$ than other media $(1.88,1.26,0.63$, and $0.31 \mathrm{mM}$ in $1 / 2 \mathrm{VW}$, MS, $1 / 2 \mathrm{MS}$, and $1 / 4 \mathrm{MS}$, respectively), was suitable for seedling development of B. nipondhii. This is in conformity with the previous reports that high $\mathrm{P}$ concentration in VW medium promoted seedling development in Bletia purpurea (Dutra et al. 2008). In contrast, this result indicated that high $\mathrm{N}$ concentration in MS decreased seedling development in B. nipondhii because the excess inorganic nitrogen in plant cells had been eliminated by nitrate reductase activity (Raghavan and Torrey 1964, van Waes and Debergh 1986).

To access the effect of pollination types on growth development of Bulbophyllum nipondhii, the seeds produced from self-, cross- and openpollination were cultured on VW medium. After 4 months, results revealed that seed germination rate was up to $91 \%$ of seeds derived from open- and crosspollination, but the seeds from self-pollination showed only $4.1 \%$ germination (Table 2). Moreover, the result showed that seeds derived from open-, cross-, and self-pollination had seedling development (in stage 5) approximately 44.0, 34.4 and $0.1 \%$, respectively (Table 2 ).

These results suggested that the germination and development percentages of seeds of open- and cross-pollination had significantly higher than selfpollination. In agreement with previous studies, which reported that seed germination produced from cross-pollination was higher than self-pollination 
Influence of Medium Component on in vitro Propagation

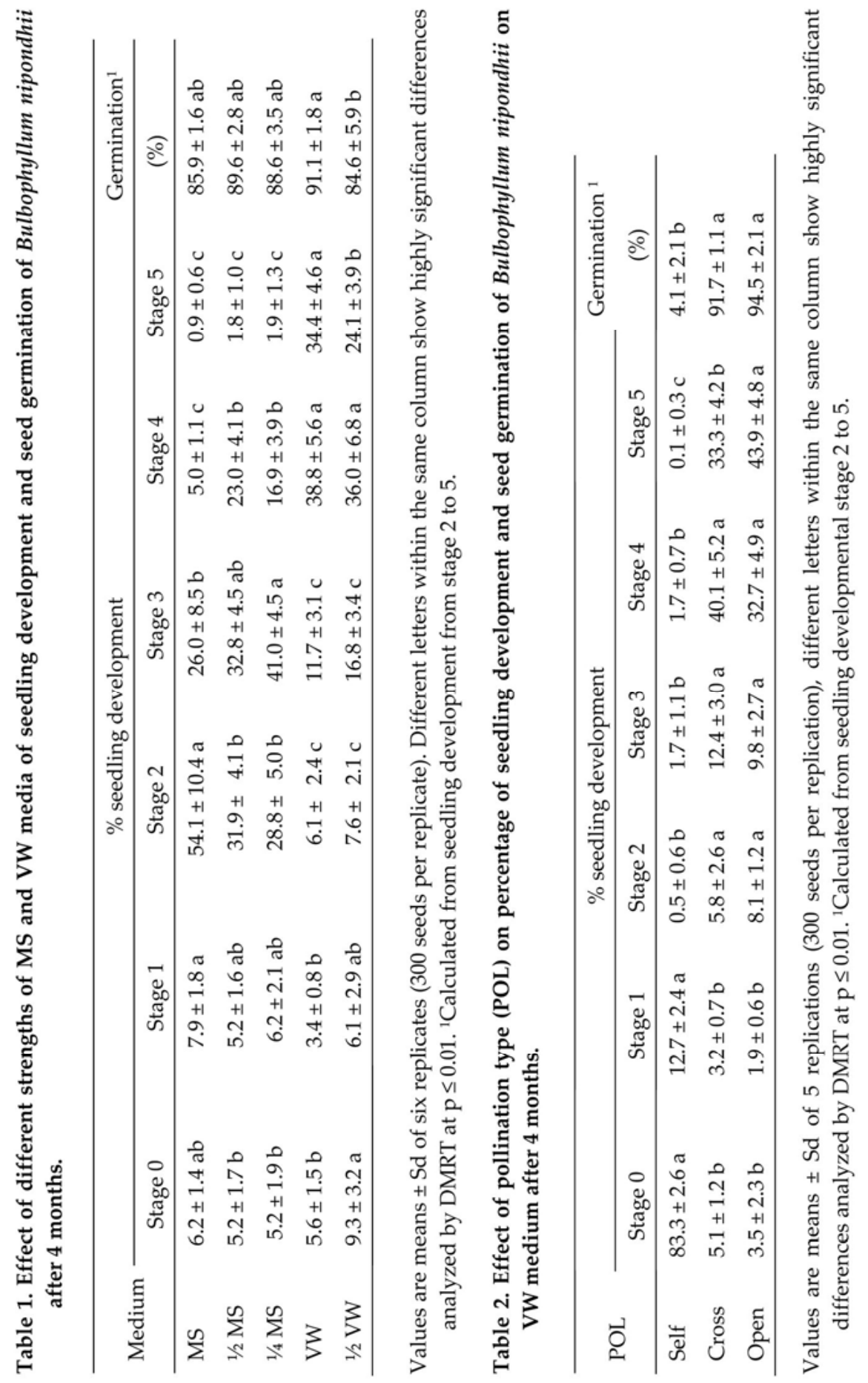


(Bellusci et al. 2009). Self-pollination may have caused inbreeding depression (Charlesworth and Charlesworth 1987, Irawati 2013), resulting in decrease rate of seed viability, seed germination and seed survival (Husband and Schemske 1995).

To examine the effect of organic supplement on proliferation of B. nipondhii, the pseudobulbs were cultured on PE (25, 50 and $75 \mathrm{~g} / \mathrm{l})$ and CW (50, 100, 150 and $200 \mathrm{ml} / \mathrm{l})$ in VW media for 6 months. At the end of the experiment, the combination of $75 \mathrm{~g} / \mathrm{l}$ potato extract (PE) and $100 \mathrm{ml} / \mathrm{l} \mathrm{CW}$ gave the best result in B. nipondhii showing a high number of new pseudobulbs (3.5), leaves (4.4), and roots (8.1), including high length of leaves $(19.2 \mathrm{~cm})$, and roots $(13.6 \mathrm{~cm})$ (Table 3 and Fig. 1c,e). Since the fresh potato contains $0.7-1.5 \%$ of the amino acid compounds (Bartova and Barta 2009), and previous studies have reported the uses of PE for the enhancement of growth of Vanda roxburgii seedlings (Islam et al. 2011), and Dendrobium officinale (Chen et al. 2014). Moreover, previous reports stated that fresh $\mathrm{CW}$ comprised of rich sugars,
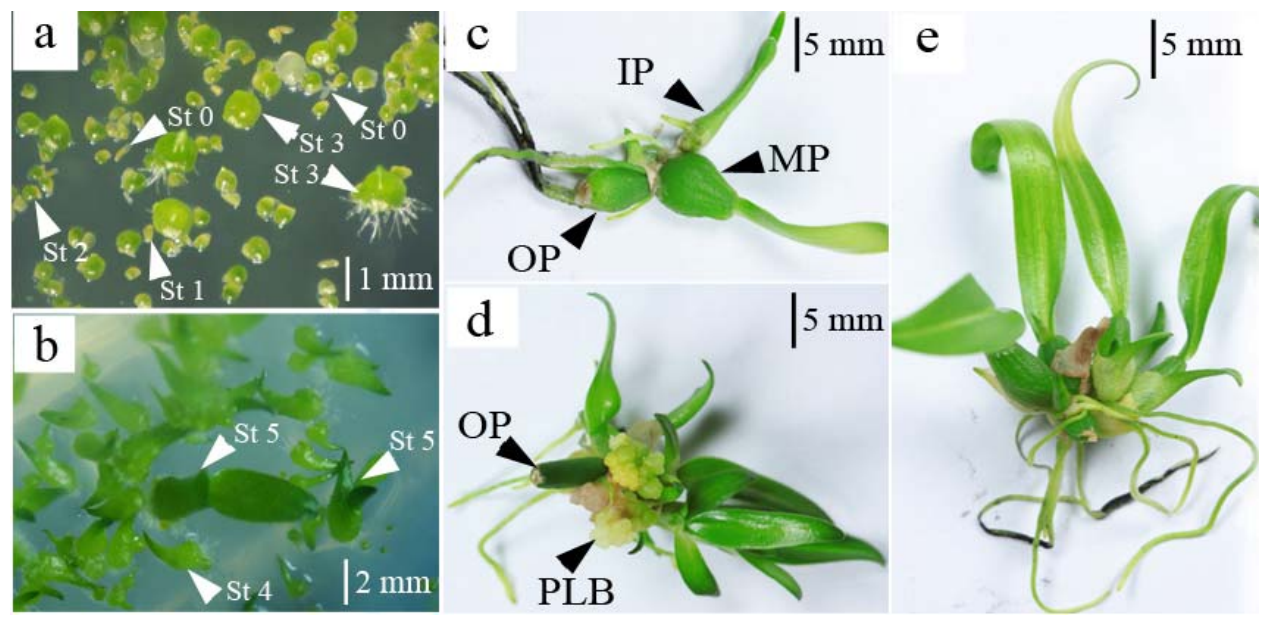

Fig. 1. Developmental stage of asymbiotic germination of Bulbophyllum nipondhii seed. a = Stage 0 (St 0 ), no development of seed; stage 1 (St 1), swollen embryo; stage 2 (St 2), embryo enlarge and testa rupture (germination stage); stage 3 (St 3), protocorm with acute apex and rhizoids. b = Stage 4 (St 4 ), emergent of first leaf; stage 5 (St 5), appearance of second leaf, root. c $=$ New mature pseudobulb (MP) and new immature pseudobulb (IP) emergence from old pseudobulb (OP). $d=$ Protocorm-like body (PLB) formation. e = Plantlet obtained from VW medium supplemented with $75 \mathrm{~g} / \mathrm{l} \mathrm{PE}$ and $100 \mathrm{ml} / \mathrm{l} \mathrm{CW}$.

vitamins, minerals, amino acids and phytohormones (Yong et al. 2009), and wildly used to enhance shoot multiplication of Phalaenopsis violacea (Gnasekaran et al. 2010) and Cymbidium pendulum (Kaur and Bhutani 2012). In the present study, the results also showed that the protocorm-like bodies were generated 


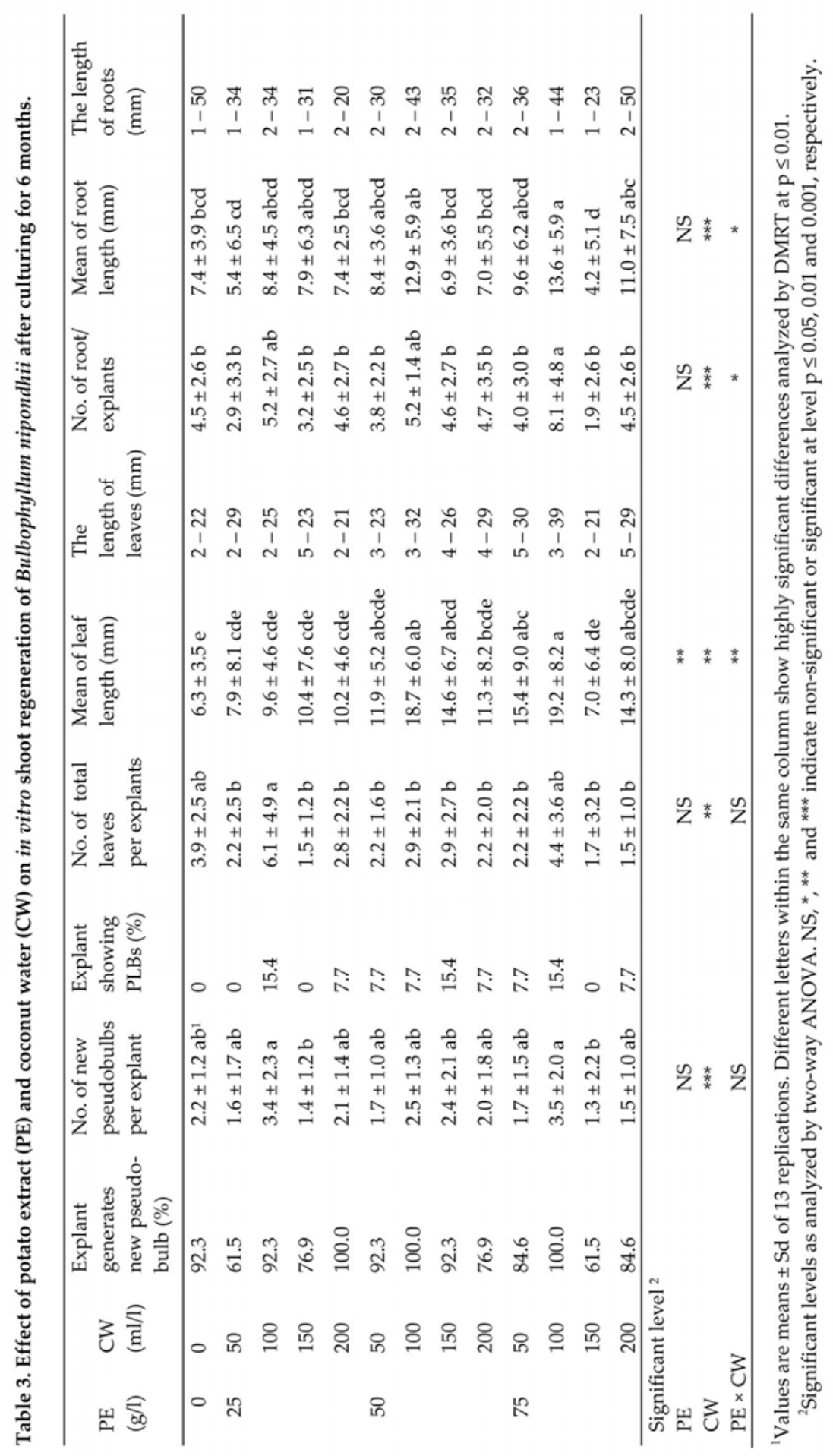


approximately $15.4 \%$ at the cutting regions of the pseudobulb cultured in VM supplemented with the combinations of PE $(25,50$, or $75 \mathrm{~g} / \mathrm{l})$ and CW $(100$, or 150 $\mathrm{ml} / \mathrm{l}$ ) (Table 3 and Fig. 1d).

The present study provided efficient methods to proliferate plantlets of Thai endangered orchid, Bulbophyllum nipondhii. Vacin and Went (VW) medium supplemented by PE $(75 \mathrm{~g} / \mathrm{l})$ and $\mathrm{CW}(100 \mathrm{ml} / \mathrm{l})$ combination was the most effective to proliferate plantlets from the orchid pseudobulbs.

\section{Acknowledgement}

The authors are grateful to the Department of National Parks, Wildlife and Plant Conservation, Ministry of Natural Resources and Environment of Thailand for the permission (No. 0907.4/3280 and 0907.4/23894) on field work study, and Mr. Chainarong Dooddurm, Head of Phuluang Wildlife Sanctuary, for field work accommodation. The authors thank Dr. Phithak Inthima and Dr. Kawee Sujipuli for their help to prepare the manuscript.

\section{References}

Arditti J and Ernst R (1993) Micropropagation of orchids. New York: John Wiley and Sons.

Bartova V and Barta J (2009) Chemical composition and nutritional value of protein concentrates isolated from potato (Solanum tuberosum L.) fruit juice by precipitation with ethanol or ferric chloride. J. Agric. Food. Chem. 57: 9028-9034.

Bellusci F, Pellegrino G and Musacchio A (2009) Different levels of inbreeding depression between outcrossing and selfing Serapias species. Biol. Plant. 53(1): 175178.

Bhadra SK, Barua H and Hossain MM (2004) In vitro germination and rapid micropropagation of Bulbophyllum lilacinum Ridley. Bangladesh. J. Bot. 33(2): 103-107.

Charlesworth D and Charlesworth B (1987) Inbreeding depression and its evolutionary consequences. Ann. Rev. Ecol. Syst. 18: 237-268.

Chen B, Trueman SJ, Li J, Li Q, Fan H and Zhang J (2014) Micropropagation of the endangered medicinal orchid, Dendrobium officinale. Life Sci. 11(9): 526-530.

Churchill ME, Ball EA and Arditti J (1972) Tissue culture of orchids-II. Methods for root tips orchid notes from UCI. Amer. Orchid Soc. Bull. 41: 726-730.

Cribb PJ, Kell SP, Dixon KW and Barret RL (2003) Orchid conservation: A global perspective. In: Orchid Conservation, Dixon KW, Kell SP, Barrett RL and Cribb PJ (Eds.), Natural History Publications (Borneo), KotaKinabalu, Sabah. pp. 1-24.

Dijk E and Eck N (1995) Anexic in vitro nitrogen and phosphorus responses of some Dutch marsh orchids. New Phytol. 131: 353-359. 
Dutra D, Johnson T, Kauth P, Stewart S, Kane M and Richardson L (2008) Asymbiotic seed germination, in vitro seedling development, and greenhouse acclimatization of the threatened terrestrial orchid Bletia purpurea. Plant Cell. Tiss. Organ Cult. 94: 11-21.

George EF and de Klerk G-J (2008) The components of plant tissue culture media I: macro- and micro-nutrients. In: Plant propagation by tissue culture 3rd edition vol. 1 the background,George EF, Hall MA and de Klerk G-J (Eds.), Springer, Netherlands, pp. 65-113.

Gnasekaran P, Rathinam X, Sinniah UR and Subramanian S (2010) A study on the use of organic additives on the protocorm-like bodies (PLBs) growth of Phalaenopsis violacea orchid. J. Phytol. 2(1): 29-33.

Husband BC and Schemske DW (1995) Magnitude and timing of inbreeding depression in a diploid population of Epiobium angustifollum (Onagraceae). Heredity 75: 206-215.

Irawati (2013) Conservation of orchids the gems of the Tropics. In: Conservation of Tropical Plant Species, Normah MN, Chin HF and M Reed Barbara (Eds.), Springer, New York. pp. 171-187.

Islam M, Akter M and Pradhan AKMA (2011) Effect of potato extract on in vitro seed germination and seedling growth of local Vanda roxburgii orchid. J. Bangladesh Agril. Univ. 9(2): 211-215.

Kaur S and Bhutani KK (2012) Organic growth supplement stimulants for in vitro multiplication of Cymbidium pendulum (Roxb.) Sw. Hort. Sci. 39(1): 47-52.

Knudson L (1922) Non symbiotic germination of orchid seeds. Bot. Gaz. 73(1): 1-25.

Molnár Z, Virág E and Ördög V (2011) Natural substances in tissue culture media of higher plants. Acta. Biol. Szeged 55(1): 123-127.

Pedersen HÆ (2005) Endemism in the orchid flora of Thailand. Oasis (Suppl. 4): 2-9.

Raghavan V and Torrey JG (1964) Inorganic nitrogen nutrition of the seedlings of the orchid, Cattleya. Am. J. Bot. 51: 264-274.

Rahman ARMM, Islam MO, Prodhan AKMA and Ichihashi S (2004) Effects of complex organic extracts on plantlet regeneration from PLBs and plantlet growth in the Doritaenopsis orchid. Jpn. Agr. Res. Quart. 38(1): 55-59.

Seaton PT, Hu H, Perner H and Pritchard HW (2010) Ex situ conservation of orchids in a warming world. Bot. Rev. 76: 193-203.

Seidenfaden G (1985) Contributions to the orchid flora of Thailand XI. Nord. J. Bot. 5: 157-167.

Shiau YJ, Nalawade SM, Hsai CN and Tsay HS (2005) Propagation of Haemaria discolor via in vitro seed germination. Biol. Plant 9(3): 341-346.

Sopalun K, Thammasiri K and Ishikawa K (2010) Micropropagation of the Thai orchid Grammatophyllum speciosum blume. Plant Cell Tiss. Organ Cult. 101: 143-150.

Than MMM, Pal A and Jha S (2009) In vitro flowering and propagation of Bulbophyllum auricomum Lindl., the royal flower of Myanmar. Acta Hort. (ISHS) 829: 105-111.

Thorpe TA, Stasolla C, Yeung EC, de Klerk GJ, Roberts A and George EF (2008) The components of plant tissue culture media. II: Organic addition, osmotic and $\mathrm{pH}$ effects, and support systems. In:Plant propagation by tissue culture, 3rd edition, Vol.1. 
The Blackground, George EF, Hall MA and de Klerk GJ (Eds.), Springer-Verlag, Dordecht. pp. 115-173.

Vacin EF and Went FW (1949) Some pH changes in nutrient solution. Bot. Gaz. 110: 605613.

van Waes JM and Debergh PC (1986) In vitro germination of some Western European orchids. Physiol. Plant. 67: 253-261.

Yamazaki J and Miyoshi K (2006) In vitro asymbiotic germination of immature seed and formation of protocorm by Cephalanthera falcata (Orchidaceae). Ann. Bot. 98: 11971206.

Ye DP and Li L (2012) Four newly recorded species of orchidaceae from China. Guihaia 32(1): 15-18.

Yong JWH, Ge L, Ng YF and Tan S N (2009) The chemical composition and biological properties of coconut (Cocos nucifera L.) water. Molecules 14: 5144-5164. 